\title{
Federalism and pandemic policies: variety as the spice of life
}

\author{
Roger D. Congleton ${ }^{1}[$
}

Received: 19 March 2021 / Accepted: 22 June 2021 / Published online: 1 July 2021

(c) The Author(s), under exclusive licence to Springer Science+Business Media, LLC, part of Springer Nature 2021

\begin{abstract}
In the ordinary course of life, choices vary with age and other factors because one's opportunities vary with one's circumstances. Thus, investments in and expenditures on healthcare (and most other things) vary with age and a variety of other factors, including whether one lives in a rural area, suburb, or central city, health risks, risk aversion, and beliefs about the nature of a good life. Because assessment of the effects of illnesses vary with the same factors, the conclusions reached about best private and governmental health policies also tend to vary. This implies that conformity to "ideal" pandemic policies is more likely to be generated by a federal or polycentric system of policy making than a unitary system, especially ones that are constrained by a generality principle.
\end{abstract}

Keywords Federalism - Covid $19 \cdot$ Pandemic policies · Political economy of federalism · Variation in rational voter opinions

JEL Classification $\mathrm{H} 1 \cdot \mathrm{I} 1 \cdot \mathrm{H} 4 \cdot \mathrm{H} 7$

\section{Introduction}

Pandemics are not new. They are old enough and occur frequently enough to have affected human nature-at least the genetic component of it. What is new are the possibilities for ameliorating them through medicines, vaccines, and public policies. This paper analyzes issues associated with the selection of public policies toward life-threatening infectious diseases. Whether such policies are feasible depends on the properties of the disease(s) of interest, state capacity, and the extent to which medical and policy interventions can limit the damage of the targeted illness(es). Policy choices, in turn, are affected by voter conclusions about the ideal and the influence of politically active interest groups, although the latter are neglected in the present analysis. ${ }^{1}$ When policies are electorally driven, the policies adopted vary with the tradeoffs associated with voter circumstances, their ideas about a

\footnotetext{
${ }^{1}$ A thorough survey of the effects of special interest/rent-seeking groups on public health policies has been undertaken by Lesson and Thompson (2021). Such groups are neglected in the present paper because of space considerations.
}

Roger D. Congleton

roger.congleton@mail.wvu.edu

1 West Virginia University, Morgantown, WV 26501, USA 
good life, and the political institutions through which such choices are made. The analysis undertaken in this paper suggests that that many, perhaps most, of the best strategies for addressing new life-threatening diseases are associated with federal or polycentric governments rather than unitary ones.

The paper begins with some biological background and then undertakes a series rational-choice-based analyses of ideal policies for individuals and communities. The first part of that analysis is undertaken with mathematical models that demonstrate that a variety of responses are likely to advance voter interests better than any single uniform response. The models demonstrate that voters tend to disagree about ideal policies even when they are all well-informed and fundamentally similar in nature. The second half of the paper demonstrates that variation in voter policy preferences implies that democratic federal or otherwise polycentric systems of governance tend to achieve outcomes that are more in accord with voter ideals during pandemics than unitary governments that impose uniform top-down policies.

\subsection{The biological context}

Pandemics arise when a bacterium, fungus, or virus penetrates human defenses against such invaders, harnesses some part of the human body to replicate itself, and spreads to other humans. Human defenses are able to overwhelm and end most such invasions, and afterwards, the associated antibodies and T-cells limit the ability of the same pathogens to reinvade previously infected persons. Such persons are said to be immune, even in cases in which the same pathogen may occasionally reinfect the same persons.

However, immunity does not extend to new pathogens, relatively un-contagious pathogens not previously confronted, and ones that exist only in regions that rarely interact with others. A subset of such novel pathogens are able to invade and, in some cases, overwhelm an individual's immune system. For example, diseases brought to the Americas by sixteenth century European explorers and settlers (such as smallpox) decimated the residents of the new world, but not the European settlers that brought and transmitted them. Europeans, likewise, had difficulties coping with diseases found in the Americas but not in Europe. Similarly, when one travels to new parts of the world, various vaccinations are often strongly recommended, such as ones for yellow fever (viral), typhoid (bacterial) and meningitis (bacterial).

As globalization continues, such regional diseases tend to become globalized and both immune responses and other genetic resistance to such diseases tend to become more universal in succeeding generations. Thus, if the population of pathogens were unchanging, humans would gradually become immune to all life-threatening funguses, bacteria, and viruses that they confront in their daily lives.

However, populations of pathogens are not entirely stable because of errors in replication (mutations). A subset of such errors occasionally produces pathogens that are more robust than the originals, and so new threats constantly arise. It is for that reason that humans are not immune to the "common cold", which is not a single disease, but a collection of illnesses with similar symptoms caused by several rapidly changing families of viruses, a subset of which manage to penetrate most human immune systems every year. It may also be for this reason that we have immune systems rather than genetically transmitted resistance to all life-threatening pathogens. Immune systems can adapt to most new invaders within a few weeks and root out invaders that might otherwise overwhelm and kill us. Because the population of pathogens changes continuously, our immune systems 
constantly cope with both new and rarely confronted pathogens. Such adaptive systems would be less useful if the population of life-threatening and crippling pathogens were entirely stable.

\subsection{The limits of medicine}

It is only a slight exaggeration to suggest that prior to 1900 no treatments for infectious diseases were available. Prior to 1900, few medicinal substances existed that would do more than mitigate pathogen-induced symptoms while one's immune system puzzled out how to repel the invader. A few vaccines had been developed during the previous two centuries, but they were not used widely and arguably were not treatments, but rather methods for triggering an immune response, so that one has the antibodies and T-cells necessary to repel a given pathogenic invader quickly-before it kills or injures the host.

It wasn't until the mid-twentieth century that antibiotics were discovered that could counter most bacteriological invaders, and a small number of anti-fungal and anti-viral treatments were developed. For the most part, fungal and viral invaders remain untreatable, or nearly so. Instead of cures for the diseases generated by such pathogens, efforts are made to ameliorate unpleasant reactions (symptoms) and to keep patients alive long enough for their immune systems to adapt to and eliminate the relevant invaders. Such efforts were still evident in the early twenty-first century's pandemic associated with the SARS-CoV-2 virus. Most people's immune system could overcome the new invader(s), but millions worldwide were unable to do so quickly enough to survive.

\subsection{Differences in human responses to pathogens}

The latter effect occurred because the capabilities of individual immune systems vary among individuals at a given age and within individuals over their lifetimes. Some individual's immune responses are more robust than others, and everyone's immune responses tend to vary with age, improving from birth through early adulthood and declining thereafter. It is for that reason that most deadly diseases kill a larger fraction of their very young and very old hosts than their middle-aged ones. Older people infected by diseases such as pneumonia, influenza, and Covid 19 die at much greater rates than middle-aged and young adults, with very young children being a bit more susceptible to such diseases than older children, and young adults, although normally far less susceptible to them than persons well beyond retirement age.

The pathogens that produce pandemics (by definition) initially are untreatable and able to overwhelm the immune response of a significant subset of the individuals infected. The discussion above implies that the likelihood that one is significantly affected by a new lifethreatening pathogen is largely determined by three conditions: (1) the probability that one will come into contact with a person or animal in the infectious phase of the disease, (2) the state of one's health when exposed to the pathogen and (3) the state of one's immune system. One cannot catch an infectious disease unless one contacts the germs that induce illnesses in humans. Whether a person's life is at risk or depends on one's initial state of health and immune response. A person that is already at death's door from other illnesses (comorbidities) may be pushed over the edge by a relatively mild infection that a healthy person hardly would notice. The speed with which an infection is repelled varies with the state of one's immune system. If one has a robust immune system or has been vaccinated, 
one may not catch the disease in the sense of developing noticeable symptoms, because the invader is repelled rapidly and easily.

\subsection{Pandemics and public policy}

Because essentially everyone prefers to be healthy rather than sick and safe rather than facing a significant risk of death, public support for policies that can reduce rates of infection at a reasonable cost, especially life-threatening infections, tend to have broad support. Of course, with novel diseases, the best policies are never obvious. Thus historically, all manner of responses have been undertaken by human communities - although few were effective (Hays, 2005). They include praying, human sacrifice, changes in diet, quarantines, and isolation. More recently, as state capacity and biological understanding increased, policies such as mandatory vaccination, subsidies for healthcare research and effective treatments, and regulating personal conduct believed to affect transmission rates have been pursued.

That a single "ideal" policy is better than a hodgepodge of independently chosen policies is a common theme in contemporary healthcare circles. For example, most discussions about the best policies for the Covid 19 pandemic of 2019-2022 asserted or assumed that a single policy would be best for countries as a whole or for the entire planet. For example, public health officials in most countries asserted that everyone should wear a mask and stay one or two meters away from all other individuals at all times whenever they left their homes. Indeed, for a short period in 2021, the Center for Disease Control (CDC) in the United States recommended wearing two masks whenever one left one's abode, rather than just one, and high government officials such as President Biden and National Institute of Allergy and Infectious Diseases (NIAID) director Fauci did so in most public appearances, although both already were fully vaccinated.

Such recommendations neglect the variation in risks that individuals living in different regions confront and also differences among individuals within those regions. When such differences are taken into account, it should be obvious-although it seems not to be-that the ideal policies for addressing pandemics are not ordinarily ones that should apply uniformly to all individuals in all circumstances. When considered from the perspective of individuals, ideal policies vary among persons and regions because of differences in circumstances and associated risks and opportunity costs. In economic terms, such considerations affect and individual's optimal tradeoffs among strategies that can promote health, reduce health risks, or otherwise enhance the quality of life.

Of course, a good life is not simply life, but a life that produces desirable outcomes for the individual or family. Good health is part of a good life, but only part of it.

\subsection{Rational choices}

The next two sections use rational choice models to show why individuals tend to disagree about the best healthcare policies for themselves and for governments. They demonstrate that disagreements tend to emerge even if people are fundamentally similar, completely rational, and perfectly informed. The models developed are not used because they are "rigorous" (although they are), but because they allow particular aspects of policymaking to be highlighted and have relatively clear implications about "ideal" solutions to such decisions. The models are similar to those that have been applied in previous studies of rational choice politics and fiscal federalism, which have generated plausible implications and withstood many empirical tests. Their main purpose is to demonstrate that fully rational 
and informed individuals tend to disagree about ideal policies because their circumstances differ. The models are very lean ones; caveats and extensions are provided in footnotes. (Those who find the assertion that well-informed individuals may disagree about ideal policies plausible and who are uninterested in how one can characterize such well-informed choices with respect to healthcare and healthcare policies might want to skip to the second half of the paper.)

\section{Differences in ideal health investments among similar individuals}

Individuals are, of course, known to differ in many ways. Humans differ in height, body weight, eye color, athletic ability, underlying health statuses, and in their abilities to learn and adapt to changing circumstances. Such differences affect all manner of behavior, including that which affects health and wealth. However, for present purposes, most such differences initially are neglected to focus on differences associated with age and geographic location. Those two differences are sufficient to demonstrate that no single policy is likely to be regarded as ideal by all well-informed voters or policymakers. Taking other differences into account, such as race, sex, ethnicity, social class, or regional histories simply would demonstrate that even more ideal policies exist than the number implied by the models developed in Sects. 2 and 3.

To simplify the model and the accompanying narrative, it will be assumed that human life encompasses three main periods or stages, young $(y)$, middle aged $(m)$, and old $(o)$, and that locations are of just two types, urban $(u)$ and rural $(r)$. It also will be assumed that health risks rise with age and differ regionally, both of which are evident in the current Covid19 pandemic as well as in previous pandemics. It likewise will be assumed that choices in one's stages of life are substantially independent of one another and wellinformed. The assumptions imply that (1) plans made when young are essentially the same as those that would have been adopted with the benefit of hindsight when middle aged or old, and (2) plans adopted by one's older self are the same as those anticipated for that period of life when young.

Individuals of the same age are assumed to be fundamentally similar, although health risks vary by age and location. Expected or average health outcomes, in turn, vary with base health, health risks, and expenditures on healthcare insurance. The individuals of interest are assumed to be rational and forward looking. They attempt to maximize a composite single objective called lifetime utility, which may be thought of as quality of life $(q)$ during life's three stages. The quality of life at each stage is modelled as a function of average health $(H)$ and material comforts $(Y)$. Average health, in turn, is determined by one's base health, location-based risks, and expenditures on healthcare insurance $\left(\mathrm{e}^{t}\right)$ in the period of interest. Average health in period $t$ thus can be represented by $H^{t}=h^{t}\left(e^{t}, L\right)$ in location, with $\mathrm{L} \cdot \in\{r, u\}$, at time $t \in\{y, m, o\}$. The average effectiveness of health insurance expenditures (e.g., health care) rises with the probability of being sufficiently ill that one benefits from healthcare expenditures. The contribution that expenditures on health insurance make to health and thereby the quality of life therefore increases with age and other risk factors. Rural areas, for example, tend to have more natural social distancing and so the residents of such areas $(r)$ face a lower risk of infection from person-to-person airtransmitted diseases than those residing in urban areas $(u)$. 
To simplify discussion and modelling, income is assumed to be determined exogenously in each period, as it would tend to be if determined by one's genotype and location at birth-although neither is being assumed here. The model simply assumes that the healthcare decisions of interest do not significantly affect current or future income. Prices are also assumed to be stable during the period of analysis, so that additional expenditures imply increases in healthcare or material comfort. Healthcare expenditures are chosen in each stage of life and the remainder of one's income during the same stage of life is devoted to material comforts. ${ }^{2}$

Given the foregoing assumptions, a young person's ideal life plan is the one that maximizes lifetime utility, which can be written as:

$$
U^{*}=\int_{0}^{T m} q^{y}\left(h^{y}\left(e^{y}, L\right), Y^{y}-e^{y}\right) \delta t+\int_{T m}^{T o} q^{m}\left(h^{m}\left(e^{m}, L\right), Y^{m}-e^{m}\right) \delta t+\int_{T o}^{T} q^{o}\left(h^{o}\left(e^{o}, L\right), Y^{o}-e^{o}\right) \delta t
$$

where the ideal pattern of personal health insurance expenditures satisfies:

$$
\begin{aligned}
e^{y} \text { is such that } \int_{0}^{T m} Q_{H}^{y} H_{e}^{y} \partial t=\int_{0}^{T m} Q_{Y}^{y} \partial t \\
e^{m} \text { is s.t. } \int_{T m}^{T o} Q_{H}^{m} H_{e}^{m} \partial t=\int_{0}^{T m} Q_{Y}^{m} \partial t \\
e^{o} \text { is s.t. } \int_{T o}^{T} Q_{H}^{o} H_{e}^{o} \partial t=\int_{o}^{T m} Q_{Y}^{o} \partial t
\end{aligned}
$$

The superscripts denote stages of life and the subscripts denote partial derivatives with respect to the variables subscripted.

Based on the income independence assumptions, Eqs. 2.1, 2.2 and 2.3 characterize typical healthcare expenditures in each period of life. They determine both health and nonhealth consumption. Three first-order conditions, each with different terms and conditions to be satisfied, imply that ideal levels of healthcare expenditures tend to vary with a person's stage in life in a given location. ${ }^{3}$ Health expenditures in each period equate the marginal increase in the value of improved health (its subjective marginal benefit) in that

\footnotetext{
2 This model neglects the existence of tax-financed insurance programs that tend to reduce the cost of obtaining medical treatment to simplify the analysis and narrative. In effect, it treats the benefits of such programs as fixed during the period of analysis, and the insurance purchases modelled can be regarded as purchases of supplemental insurance. For a public choice analysis of how income and risks affect the characteristics of tax-finance healthcare programs, see Congleton, Batinti and Pietrantonio (2017). The discussion and analysis based on the model go through as long as individuals make any out-of-pocket expenditures on healthcare or supplemental health insurance. For example, the costs of masks, self-isolation, and economic shutdowns generally been borne by individuals rather than through socialized medicine.

${ }^{3}$ For example, according to the CDC, the risks of death and hospitalization from Covid 19 rise with age. The risk of death for persons between 65 and 74 is 90 times greater and for those over 85 more than 600 times greater than that of persons in their twenties. See: https:/www.cdc.gov/coronavirus/2019-ncov/coviddata/investigations-discovery/hospitalization-death-by-age.html Approximately, 95\% of those who died from Covid 19 were over the age of 50 .
} 
period with the marginal reduction in the value of one's material comforts (its subjective marginal cost) in that period. ${ }^{4}$

Together with the observed character of health risks, the three first-order conditions imply that health expenditures rise with age. ${ }^{5}$ In the normal course of life, one's base health falls with age from young adulthood onward and risks associated with pathogens increase. If income in the three stages were the same, expenditures on healthcare would be lower when young than when middle aged, and lower when middle aged than old, because base health falls and health risks increase as one ages, both of which increase the net increase the quality of life associated with additional healthcare expenditures at the margin. ${ }^{6}$

The usual rise in personal and family income associated with being middle aged tends to widen differences in health expenditures between the first two periods of life. The decline in income from the middle aged to the old period tends to reduce the difference generated by differences in (expected) base health and increases in the marginal utility of healthother things being equal. The net effect depends on the anticipated decline in health (and associated increase in the marginal utility of health expenditures) and the anticipated decline in income (and increase in the marginal utility of material comforts). Relatively more is spent on healthcare in the final period of life whenever the effect of a decline in base health and increase in health risks exceed the effect of reduced income. ${ }^{7}$

Rationality and the importance of health and material welfare imply a universal demand for healthcare, but differences in base health, health risks, and wealth imply that there is not a universal demand for a particular level of health insurance. It is important to keep in mind that disagreements about the ideal level of health insurance (and risk avoiding activities) in this model occur because of differences in circumstances rather than differences in knowledge or propensities to make mistakes. Persons of each age are assumed to know all that can be known about their own health, income, and the precise manner in which health insurance and its associated healthcare expenditures improve health in every period.

If healthcare and material comforts both were private goods without externalities and were sold in competitive markets, the usual welfare economics implications of competitive markets would apply to the equilibrium that emerges from consumer and supplier competition and choices in markets for healthcare. The result would be Pareto efficient. Although the equilibrium would not satisfy all possible theories of the "good society", no alterations of the equilibrium are possible that would make one person better off without making another worse off. Thus, any change would violate the "do no harm" principle.

\footnotetext{
${ }^{4}$ In this and the following models, the usual geometric assumptions necessary to assure strict concavity in the lifetime utility function are assumed, unless otherwise indicated.

5 Of course, differences in first-order conditions do not entirely rule out the possibility that a single level of healthcare will be adopted in each stage of life, but given the continuum of healthcare, those differences make it highly unlikely.

6 The models and discussion focus on private health insurance, rather than direct healthcare expenditures, because the latter tend to be small, although they are not always unimportant. However, insofar as such expenditures and the inconveniences of other steps that reduce disease transmission can be monetized, they can easily be included as part the expenditures modelled.

7 Note that this model neglects the possibilities of shifting income across stages of life through credit markets. When perfect credit markets exist, individuals can access their lifetime incomes during period Y, which tends to generate income smoothing-borrowing when young, saving when middle aged, and dissaving when old-which reduces the effects of differences in income among age groups. In the limit, such smoothing, in effect, generates the same income in every period. In that case, the logic of the discussion based on holding income constant becomes more general and still implies that healthcare expenditures tend to rise with age.
} 
The effect of urban and rural locales on healthcare choices implies six different personally ideal combinations of health insurance spending in a population characterized by two types of regions and three stages of life. The base model clearly demonstrates that agreements about ideal levels of private health care (and associated risk-reducing activities) are extremely unlikely even when essentially all complicating factors are ignored. Differences in age and location are sufficient to generate such differences even when everyone is essentially similar, well-informed, and forward looking.

\section{Healthcare externalities and the demand for public pandemic policies}

The next section explores why most forward-looking, well-informed, self-interested, pragmatic voters at different stages of life and living in different places favor subsidies for healthcare and transmission reducing behavior. Such behavior reduces negative externalities (risks and rates of illness) which thereby can be regarded as generating significant positive externalities relative to baseline behavior. It also shows why such voters nonetheless tend to disagree about the ideal level of such subsidies and other policies that might be adopted to address health externality problems.

Most human diseases generated by germs are passed from one person to another and so negative externalities are associated with respect to behaviors such as coughing or sneezing in public, interacting repeatedly with other persons while ill, and to some extent by the use of symptom-reducing medicines that hide the fact that one is contagious. Contrariwise, choices that reduce the spread of a disease generate positive externalities by reducing transmission rates. Such behaviors include vaccinations, various degrees and qualities of masking, self-isolation, and so forth. Such contagion externalities differ from the ones normally modelled in public economics textbooks only because they are probabilistic rather than deterministic and because the extent of the externality varies during the course of a pandemic. None of the above behaviors necessarily affect anyone else's health; rather, such behaviors affect the probability that others will contract the disease of interest. "Appendix 1" illustrates and discusses the nature of such contagion externalities in more detail. ${ }^{8}$

If significant externalities exist, it is well-known that the equilibrium that emerges from competitive markets is unlikely to be Pareto efficient, in which cases there would be unrealized mutual gains that could be realized by incentivizing or coordinating

\footnotetext{
${ }^{8}$ Here and in "Appendix 1", I am accepting the CDC and WHO characterization of the transmission of most respiratory diseases. Overall risks are increased by such behaviors only in the short run, that is, in the period before effective vaccines become widely available, as illustrated in "Appendix 1". If such vaccines are not possible, then transmission reducing behaviors affect only the timing of the infection rather than its cumulative probability. In the absence of an effective vaccine, essentially everyone is likely eventually to be infected by a highly contagious disease, regardless of the behavior of others, as it gradually spreads throughout a population composed entirely of susceptible persons. See, for example, Ferguson et al. (2020).

In such cases, the health externalities have to do with the timing of infections rather than infection risk per se. The timing effects affect the timing of hospital demand(s) and their abilities to treat persons both for the disease of interest and other health conditions. When hospital demand is greater than capacity, many critically ill patients necessarily go untreated. Such timing effects thereby affect the marginal product of healthcare expenditures and insurance.
} 
externality-generating behavior, as pointed out by Pigou (1920) in his classic work on welfare economics, Coase (1960) in his subsequent analysis of the reciprocal nature of many externalities, and in virtually every public economics textbook. ${ }^{9}$

When positive externalities are large and affect all age groups and regions, most voters will favor public policies that encourage behaviors that reduce health risks for others and discourage those which increase them. As a consequence, many such policies are likely to be adopted, as with formal rules mandating particular vaccinations for school-aged children, subsidies for healthcare research and development, and policies that encourage various forms of self-isolation. When the marginal health benefits of such behaviors are not distributed uniformly, however, differences in the demand for public policies that encourage such behavior would arise even in cases in which all voters prefer policies to do so.

The next subsections develop two rational choice models. The first characterizes the extent of externality generating behavior by individuals, and the second demonstrates why a voter's policy preferences with respect to such behaviors are likely to be affected by age and location. The main purpose of the models is to show that even forward-looking wellinformed individuals who are fundamentally similar tend to disagree about ideal governmental pandemic policies.

\subsection{Healthcare externalities}

Let us return to the base model and extend it to include externality-generating behavior $\left(x^{t}\right)$, and the external effect of the externality-generating behavior of all others (X). It is obvious that some expenditures on healthcare have no or only trivial effects on others, while others have significant effects. That difference can be characterized by dividing healthcare expenditures into two types: purely private ones $\left(e^{t}\right)$ and those that generate positive externalities $\left(x^{t}\right)$. Some of the coverage provided by private insurance and other personal expenditures on healthcare can be regarded as generating no externalities, while other coverage, as well as direct and indirect expenditures on vaccines, anti-viral drugs, masking, and self-isolation tend to generate positive externalities relative to the absence of such behavior.

The aggregate external effect of the externality generating behavior $(\mathrm{X})$ is an increasing function of the externality-generating behavior of all others, as with $X_{j}=\sum_{i \neq j}^{N} x_{i}^{t^{*}}$ for the

Footnote 9 (continued)

petition among firms may internalize healthcare externalities without government intervention. The benefits of such internalization would tend to increase with the effectiveness of medical treatments and, hence, owners may spend more on healthcare and health insurance through time.

That externalities may exist, and yet competitive equilibria nonetheless may be Pareto-optimal even without internalization was noted in Buchanan and Stubblebine (1962) and indirectly by Bentham (1789). Externalities have to exist "at the margin" and the policies adopted have to be cost-effective to be Paretorelevant, which is assumed in the above analysis.

9 Such healthcare externalities are commonplace-more so than often is recognized. Moreover, organizations other than governments may take steps to internalize them. For example, insofar as firms make use of team production, illnesses of team members tend to reduce the productivity of other team members, reducing a firm's output and profits. That externality provides firm owners with incentives to reduce transmission rates (as with sick days and air filtration) and subsidize healthcare for their employees. In such cases, com- 
externality borne by individual $\mathrm{j} .{ }^{10}$ In a large number setting, the aggregate externality is essentially unaffected by an individual's own activities and so it is assumed that the aggregate externality is the same for all individuals living in a given region $X_{j}=X_{i}=X^{L}$.

Choices with respect to the two kinds of healthcare expenditures can be characterized as follows. Lifetime utility becomes:

$$
\begin{aligned}
U^{*}= & \int_{o}^{T m} q^{y}\left(h^{y}\left(e^{y}, x^{y}, q^{L}, L\right) Y^{y}-\left(e^{y}+x^{y}\right)\right) \delta t \\
& +\int_{T m}^{T o} q^{m}\left(h^{m}\left(e^{m}, x^{m}, X^{L}, L\right) Y^{m}-\left(e^{m}+x^{m}\right)\right) \delta t \\
& +\int_{T o}^{T} q^{o}\left(h^{o}\left(e^{o}, x^{o}, X^{L}, L\right) Y^{o}-\left(e^{o}+x^{o}\right)\right) \delta t
\end{aligned}
$$

And the first-order conditions characterizing ideal choices become:

$$
\begin{aligned}
e^{y} \text { is s.t. } & \int_{0}^{T m} Q_{H}^{y} H_{e}^{y} \partial t=\int_{0}^{T m} Q_{Y}^{y} \delta t \\
e^{m} \text { is s.t. } \int_{T m}^{T o} Q_{H}^{m} H_{e}^{m} \delta t & =\int_{T m}^{T o} Q_{Y}^{m} \delta t \\
e^{o} \text { is s.t. } \int_{T o}^{T} Q_{H}^{o} H_{e}^{o} \delta t & =\int_{T o}^{T} Q_{Y}^{o} \delta t \\
x^{y} \text { is s.t. } & \int_{0}^{T m} Q_{H}^{y} H_{x}^{y} \partial t=\int_{0}^{T m} Q_{Y}^{y} \delta t \\
x^{m} \text { is s.t. } & \int_{T m}^{T o} Q_{H}^{m} H_{x}^{m} \delta t=\int_{T m}^{T o} Q_{Y}^{m} \delta t \\
x^{o} \text { is s.t. } & \int_{T o}^{T} Q_{H}^{o} H_{x}^{o} \delta t=\int_{T o}^{T} Q_{Y}^{o} \delta t
\end{aligned}
$$

Those six first-order conditions characterize the externality-generating behavior of six types of individuals, ones that are young (with all terms and all six first-order conditions), middle aged (with only the $m$ and $o$ terms and the last four first-order conditions), and old (with only the $o$ terms and the last two first-order conditions). Each of the three age types may live in either a rural $(L=r)$ or urban setting $(L=u)$ with differences in their associated health risks and, hence, the average or expected productivity of health expenditures. The first-order conditions are notationally similar for the six types of individuals, but they

\footnotetext{
${ }^{10}$ Here, it should be acknowledged that the effects might not rise linearly with externality producing behavior. Simple nonlinear effects can be modelled in the same manner as above; others would require $\mathrm{X}$ to be more carefully modelled. However, for the purposes of this paper, all that is necessary is that aggregate externalities rise as other people engage in externality generating behavior. This implies that a demand for externality reducing policies is likely to exist, while differences in the circumstances among individual voters implies that their conclusions about "ideal" policies tend to differ.
} 
generally imply different optimal mixes of private and externality generating expenditures. Both private and externality-generating healthcare expenditures tend to vary with age and location.

Ignoring corner solutions, the model implies that some positive externality generating expenditures are undertaken by each type of individual, but the levels vary and their effects on others vary with the age and location of the persons affected. Location has effects on externality generating behavior because of differences in what might be called "natural social distancing", which tends to be greater in rural areas than in urban ones.

\subsection{Support for subsidies of behaviors that have positive externalities}

The demand for the public policies modelled in this section of the paper arises because of the effects of externalities (X) on the marginal productivity of healthcare. The lower base health is for the average person of age $t$ in location $L$, the greater is the marginal productivity of healthcare expenditures. (A healthy person with a very robust immune system benefits little if at all from such expenditures.) The effect of the aggregate externality thus varies with the age distribution of the relevant group and its location, with older urban residents being most affected and young rural residents being the least affected-other things being equal-because of differences in base health and population density.

Rather than mandates, the public policy under consideration is assumed to be a subsidy that encourages behavior (here expenditures) that generate positive externalities. ${ }^{11}$ In the case of life-threatening pathogens, it is possible to subsidize and other wise encourage behaviors that reduce baseline transmission rates such as social distancing, masking indoors, and being vaccinated. Transmission rates also tend to fall as working at home online rather than in an office is encouraged by reductions in taxes (generated, for example, by deductions for home computers and cameras).

What is important for this paper is not the specific ideal policy characterized or its associated conditions for optimality, but that no single government policy is likely to be ideal for all voters-even when voters are well-informed and make no mistakes in their policy assessments.

A minor extension of Eq. 3.0 allows the ideal policy to be characterized for an individual of given age and location. Externality $\mathrm{X}$ is now written as a function of subsidy $S$. An earmarked income tax is assumed to be collected and used to finance the subsidy, $T=g\left(S, Y^{t}\right)$. Each person's ideal subsidy is the one that maximizes their lifetime utility (Eq. 5). Such policies satisfy first-order conditions notionally identical to those of 4.1 through 4.6, plus a new one listed below (Eq. 5.1). Lifetime utility becomes:

\footnotetext{
11 Mandates $(m)$ that increase positive externalities while reducing material comforts can be modelled with essentially the same equations by replacing the tax price $(T)$ with the personal cost $(C)$ of a mandate $(\mathrm{m}), " \mathrm{C}=\mathrm{c}(\mathrm{m})$ ", and writing the aggregate externality $X$ as a function of $m$ rather than $S$. Inexpensive mandates supported by monetary penalties could be represented with an expected fine function similar to the tax function assumed. However, modeling positive externalities associated with the R\&D efforts of firms and scientists that tend to bring effective vaccines to markets more quickly would require a more complex model, similar to that developed in Batinti and Congleton (2018). The purpose of the modelling exercise in this paper is to demonstrate that policy disagreements are likely among even similarly well-informed individuals, rather than to fully characterize the political economy of healthcare systems.
} 


$$
\begin{aligned}
U^{*}= & \int_{o}^{T m} q^{y}\left(h^{y}\left(e^{y}, x^{y}, X(S) \cdot R\right), Y^{y}-\left(e^{y}+x^{y}+g\left(S, Y^{y}\right)\right)\right) \delta t \\
& +\int_{T m}^{T o} q^{m}\left(h^{m}\left(e^{m}, x^{m}, X(S), R\right), Y^{m}-\left(e^{m}+x^{m}+g\left(S, Y^{m}\right)\right)\right) \delta t \\
& +\int_{T o}^{T} q^{o}\left(h^{o}\left(e^{o}, x^{o}, X(S), R\right), Y^{o}-\left(e^{o}+x^{o}+g\left(S, Y^{o}\right)\right)\right) \delta t
\end{aligned}
$$

And the ideal subsidy for a person of a given age and location, $\mathrm{S}^{*}$, satisfies:

$$
X_{S}\left(\int_{T o}^{T m} Q_{H}^{y} H_{W}^{y} \partial t+\int_{T m}^{T o} Q_{H}^{m} H_{W}^{m} \partial t+\int_{T o}^{T} Q_{H}^{o} H_{W}^{o} \partial t\right)=T_{S}\left(\int_{0}^{T m} Q_{Y}^{y} \delta t+\int_{T m}^{T o} Q_{Y}^{m} \partial t+\int_{T o}^{T} Q_{Y}^{o} \partial t\right)
$$

Together, the system of first-order conditions (4.1-4.6 and 5.1) characterizes an individual's ideal pattern of healthcare expenditures, material comforts, and subsidy-given the fiscal implications of the preferred subsidy as well as their own tradeoffs between health and material comfort. ${ }^{12}$ The first-order conditions are not fully separable in this case because of after-tax induced adjustments to income and healthcare expenditures associated with increases in the subsidy. Nonetheless, each first-order condition sheds useful light on individual preferences over expenditures and policies, given ideal levels of the other control variables. ${ }^{13}$

Equation 5.1 can be used to characterize the ideal pandemic policy (subsidy, $\mathrm{S}^{*}$ ) for a young person-given his or her ideal patterns of lifetime expenditures on healthcare and other goods and services. It implies that a forward-looking well-informed young person accounts for the effects of a permanent subsidy over his or her entire course of life. The analogous first-order condition for middle-aged persons would exclude the first terms (those with y superscripts), and thus take account only of his or her present period of life and that during retirement. The first-order condition for older persons would include only those with $o$ as superscripts. (The ideal level of a temporary subsidy is characterized by the terms that are relevant for a voter's current stage of life.)

The differences in first-order conditions imply that the ideal subsidy levels differ among voters because age-related differences in circumstances and because older persons all ignore the effects of higher tax bills on those younger than themselves. The same conclusion applies to subsidies that are expected to be short lived, in which case, voters may focus only on their current period of life or age, which tends to imply even larger differences. ${ }^{14}$

In addition to the variation in ideal policies generated by age, differences in ideal subsidy levels also arise among persons of similar ages across regions. The diminution in health risks associated with the externality and therefore the marginal effects of behavioral

\footnotetext{
12 The simplest explicit representation would be: $X(S)_{j}=\sum^{N}(1+S) x_{i}^{t^{*}}$.

13 Equation 5.1 is an accurate but simplified way of writing $i \neq j$ the relevant first-order condition for ideal subsidy levels. It is calculated along the envelope of ideal patterns of the two forms of healthcare and nonhealthcare expenditures characterized by Eqs. 3 and 4.1 through 4.6. Insofar as these are determined partly by $\mathrm{X}$, a more detailed characterization of the derivatives of $\mathrm{S}$ would include adjustments to all expenditures. The version provided is sufficient to make it clear that assessments of ideal subsidy levels would vary by age and location.

14 To this point, the assumption that all persons have only narrow self-interests has been adopted as in most rational choice-based modelling. Other normative interests voters might have are taken up later in the paper.
} 
changes induced by the subsidy differ in both objective and subjective terms, because differences in population density imply differences in the marginal benefits associated with reduced transmission risks.

Consequently, voter demands for public policies that encourage the generation of positive healthcare externalities tend to vary with age and region. Each of our six types of wellformed, self-interested individuals prefers a different universal pandemic-reducing subsidy. A consensus does not exist because of relevant differences in circumstances.

If we assume that income can be smoothed through time using capital markets, marginal effects of such policies on personal health risks largely determine policy preferences. In that case, the ideal subsidy ( $\mathrm{S}^{*}$ ) tends to increase with age because positive externalities reduce health risks more for older folks than younger folks. Insofar as reductions in rural risks (transmission rates) are lower than urban ones, persons living in rural areas would favor smaller subsidies than those living in urban areas, other things being equal.

Overall, differences in health risks associated with age and regions imply that no single "ideal" universal policy exists from the perspective of well-informed self-interested individuals. $^{15}$

\subsection{The median voter and pandemic policy}

Of course, a lack of a consensus does not imply that no governmental policies will be adopted, because policies in democracies are not based on unanimous agreement but various forms of majority rule and delegated authority. It does, however, imply that people will disagree about the merits of any universal policy chosen.

Spatial voting models imply that policies (when an equilibrium exists) tend to be drawn toward the median voter's ideal point, which in many cases will be that of middle-aged voters living in urban areas, especially if the suburbs are considered urban. Middle-aged persons living in urban areas are the largest population group in the United States and according to the model above tend to have intermediate demands for healthcare and subsidies for positive healthcare externalities. ${ }^{16}$

Recall that it is being assumed that all individuals are perfectly informed and make no errors in their assessments of ideal policies for themselves, given their location and age. In that case, the median voter's idea is ideal for all of his or her compatriots in the same region and of the same age. Nonetheless, significant disagreements exist between the median group and their younger and older neighbors as well as for persons of the same age living in different regions.

\footnotetext{
15 The same logic applies to other methods of encouraging or discouraging health externality generating activities, such as mandates and fines. Characterizing such policies would require further adjustments to the model. Disagreements among voters in different age groups and regions will tend to emerge for such policies as well for the same reasons as developed in the model used above.

16 The term middle age - as used here, people who are raising or have recently raised a family, have chosen and pursued a career, and are actively engaged in both family and career-oriented activities-may be regarded as persons between the ages of roughly 30 and 62. The 2010 US Census does not adopt those thresholds but does allow the number of persons between the age of 25 and 64 (52\%), those between 18 and $24(9 \%)$ and those older than $65(40 \%)$ to be calculated (2010 Census Briefs, Age and Sex Composition 2010, May 2011). The 2010 Census regards 250 million persons ( $80 \%$ of Americans) to be living in urban areas (see https:/www.census.gov/programs-surveys/geography/guidance/geo-areas/urban-rural/ua-facts. html).
} 
Such disagreements are not mere matters of opinion; they are contextual in nature. Every voter modelled up to this point favors policies that are truly ideal given their age and location. Policy disagreements do not require voter ignorance or short sightedness, as often suggested by widely read urban newspapers and websites.

\section{Federalism, democracy, and variety in pandemic policies}

The same model of policy preferences and voter-driven public policies can be applied to predict the policies of any competitively elected level of government with authority over a subset of pandemic policies. In the case of decentralized systems of governance with elected mayors, governors, and legislatures, state policies are likely to vary because of differences in the age and location of pivotal voters in city and state electorates-even if voters are all perfectly informed and vote in accord with their own self-interest. Thus, differences in city and state policies tend to emerge even in cases in which voters are all well informed and forward looking as assumed until now in the present paper.

In cases in which intrastate externalities are much greater than interstate externalities and the ideals of state and regional voters are more similar than those of the entire nation, the resulting patchwork of electorally driven public policies tends to be superior to any single uniform policy according to mainstream welfare economics. In such cases, Oates's (1972) decentralization theorem applies, and decentralized policies would generate a better matching of policies to state or local voter preferences and circumstances than any uniform national policy can.

Figure 1 provides the essential geometry of Oates's decentralization theorem. It illustrates the advantages of policy diversity for the median voters of two states, cities, or regions entitled to select a subset of pandemic policies. Their respective marginal benefit and marginal cost curves are the left- and right-hand sides of their respective Eq. 5.1, given ideal values for the other choice variables. Their respective marginal cost curves are assumed to be horizontal and identical simply to make the diagram easier to interpret. Given their marginal benefits and marginal costs, the two median voters have different ideal policies, as would be the case if they were of different ages or one lived in an urban area and the other in a rural area.

The median voter of state A, possibly one dominated by rural voters, prefers subsidy or regulatory target $\mathrm{Q}^{\mathrm{A} *}$ and that of state $\mathrm{B}$, possibly one dominated by urban voters, prefers $Q^{B}$, with $Q^{A *}<Q^{B}$, because those values maximize their respective net benefits (or lifetime utility). Note that any uniform national standard between those two ideals causes each to be worse off. The median voter of state A loses net benefits equal to area I and the median voter of state B loses net benefits equal to area II.

An intermediate solution might be a reasonable compromise if a single uniform policy had to be adopted; however, decentralized systems of governance allow policies to vary among regions, which makes the median voters of each state or region better off-and a majority, although not all, of their respective citizens better off as well. ${ }^{17}$

\footnotetext{
17 Some caveats are necessary here. Some regions of some states are more intimately connected than others, for example, northeastern New Jersey, and southwestern Connecticut are both commuter homes for persons working in New York City, and all three subregions of their respective states were among the most seriously affected by the spring 2020 peak in Covid infection rates and deaths. Similarly connected subareas exist around several other major cities, as with the Maryland and Virginia suburbs of Washington DC. It would make sense for such closely connected regions to coordinate their policies; however, seven of the 10 most populous US cities and their associated commuting regions are within single states. In those cases,
} 
If middle-aged persons determine policies, and their interests differ because of differences in population density, two general types of policies would be adopted-one for states dominated by middle-aged urban voters and one for states dominated by middle-aged rural ones. This is, of course, a reasonable first approximation of the policies observed in the United States during the first year of responses to Covid-19. A more fine-grained characterization of the continuum of ages and urbanization would imply even greater variety of ideal policies among state median voters and elected officials.

\section{Differences in information and expectations associated with new pathogens}

Of course, age and population density are not the only factors that vary among individuals. States and regions also differ in their histories and in the ethnic characters of the persons residing in them, which reflect different histories of migration and emigration into and out of them. Differences in genetic endowments and intra-family cultures are likely to produce additional differences in tradeoffs between health and material comforts as well as differences in health risks associated with particular contagious diseases. Such differences would produce additional variation among state median voter preferences over pandemic policies.

However, let us continue to assume that people are all fundamentally the same and explore two other less tangible influences on their public policy preferences, namely differences in information and differences in internalized norms that affect policy a voter's policy preferences.

This subsection focuses on the implications of informational differences and the next one on differences in norms or ideology. Informational differences in conclusions reached about a new pathogen may emerge because of differences in the accessibility of information, interest in obtaining it, and the opportunity cost of transforming the data collected into useful knowledge. Larger datasets can always be collected, and more or less time can be spent analyzing the data assembled, but time and attention are scarce resources. Fortunately, even a small amount of representative information allows one to form expectations that on average produce the results anticipated. It is only with respect to choices in which one's dataset is unrepresentative that expectations tend to be biased and individuals tend to be mistake-prone in assessments of their own interests (Congleton, 2001, 2007).

Such biases, however, are likely for novel pathogens because of their initially unknown properties, small datasets, and the various plausible interpretations of the truncated datasets assembled. Much needs to be known to make informed decisions about a new lifethreatening contagious disease, as with its manner and degree of contagion, its health consequences, and survival rates for different types of individuals and treatments.

Newness implies that ignorance and other informational problems arise for both experts and nonexperts. Early datasets tend to be small, truncated, and otherwise unrepresentative

Footnote 17 (continued)

delegation of authority to urban and rural counties (or regions) within states would make good sense, insofar as they may be regarded as more or less independent "bubbles" of health externality risks. The "bubble assumption" of the analysis above becomes more or more realistic as travel declines, social distancing norms intensify, and public policies that reduce transmission rates are adopted and followed by all or most interdependent "bubbles". 
Fig. 1 The geometry of the decentralization theorem

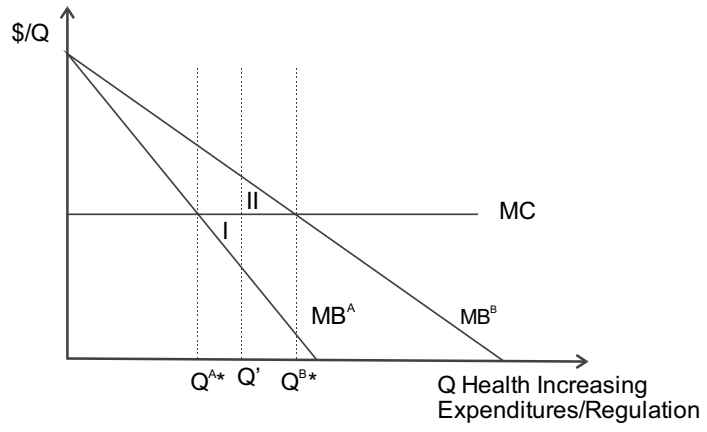

of the full range of data that eventually will be assembled. Consequently, biased expectations and mistakes are associated with new diseases and other emergencies (Congleton, 2004). How large the mistakes are varies with the relevance of the unknown and underanalyzed properties of a new health risk for the decisions at hand.

Although experts may acquire information more rapidly and interpret it more carefully than nonexperts do; initially, they, too, do not know all that would be useful about a new pathogen and its associated transmission and illness(es). When the facts initially collected are open to different reasonable interpretations (ones that are logically consistent and that do not conflict with the available data), both honest experts and voters may reach different conclusions about the risks and best strategies for ameliorating those risks. Meta studies of economic research suggest that the variation in well-reasoned and plausible estimates can be considerable even for mature areas of research. (See, for example, Doucouliagos et al., 2018). However, meta studies generally find that the variation among models and coefficient estimates are larger in early studies than later ones.

Such differences produce a third source of variation in both private choices and policy preferences in addition to age and location. For example, middle-aged persons living in urban areas might disagree on personal health strategies and public policies because they have reached different conclusions from the data available at the moment when such decisions have to be made (data in most cases consisting of stories read or heard, cases seen, and quantitative data examined). Even in circumstances in which all individuals have fundamentally identical interests, as in the models developed above, differences in conclusions about the risks, effectiveness of treatments and public policies tend to produce different conclusions about the best personal behavior and public policies.

In terms of the models, otherwise identical individuals that rely upon different truncated information sets tend to have different understandings of the health production function because of differences in their estimates of the effectiveness of healthcare and alternative policies. Such differences would induce differences in personal behavior and assessments of the relative merits of public policies for the same reason that differences in regions and age do.

If, for example, just two reasonable interpretations of the available data were possible, our six-fold characterization of ideal public policies above becomes a 12-fold characterization that now is partly generated by informational differences. ${ }^{18}$

\footnotetext{
18 Many reasons can be found explaining why expert scientists may reach different conclusions from the same datasets. The simplest in Bayesian terms is that scientists often hold different priors about the world before confronting the data. Sowell's (2002) less statistical notion of "visions" also may affect both interpretations of facts and their assessments of their implications for private health strategies and ideal public policies.
} 
In times of crisis, everyone is ignorant of relevant details and mistake-prone, because decisions have to be made quickly with insufficient data and analysis. Some doctors and policy makers will "get it right" through good fortune, rather than wisdom or insight. But, initially, there are no truly "best" policies that should be adopted by all individuals in similar circumstances, because of entirely reasonable and unavoidable variations in theories and associated parameterizations of the health production function.

These facts, however, do not imply that there are no sensible choices. Even in new circumstances, many similarities can be found with previous ones. For example, most respiratory infections are transmitted in more or less similar ways, so recommendations about how to slow the spread of such diseases tend to be similar. Thus, the Center for Disease Control's (CDC's) recommendations about how to slow the spread of Covid 19-with social distancing, hand washing, and coughing/sneezing into tissues or elbows-were initially exactly the same as those previously recommend for the flu and other respiratory diseases caused by viruses. ${ }^{19}$ Nonetheless, it is to say that such sensible recommendations tend to be error-prone, because of unknown differences between a new disease and old ones. For example, the initial recommendation about the use of ventilators for life-threatening cases of Covid-19 turned out to be incorrect and generated greater fatality rates than later guidance for using them. Similarly, the effects of restricting outdoor activities on transmission rates were much smaller than initially believed by many policy makers. ${ }^{20}$

The news media, if anything, tends to reinforce tendencies for mistaken policies by focusing attention on the outliers of early research. For example, with respect to Covid19, worst-case scenarios by Imperial College (Ferguson et al., 2020) and best-case assessments based on infection rates among tourists on the Diamond Princess Cruise ship drew far more press attention than intermediate estimates. ${ }^{21}$

\subsection{Federalism and policy experimentation}

Given different samples of the initial studies from which to choose, state policymakers (and state voters) are likely to reach different conclusions about ideal policies, with the result that additional policy variation is introduced by the theories and early empirical results

\footnotetext{
Footnote 18 (continued)

Additional variation would be introduced because of differences in the scope of ignorance or biased information. Different persons might, for example, collect information only about a subset of the characteristics of a disease or the benefits and costs of a given treatment for it. Such choices necessarily are mistake-prone, even if individuals make the very best use of the information they do have (Congleton, 2001, 2007).

19 See, for example, https://www.cdc.gov/flu/pdf/freeresources/updated/everyday-preventive-actions-8. $5 \times 11$.pdf.

${ }^{20}$ Meta studies of research programs nearly all find exaggerated claims to be commonplace when a research program begins. See, for example, Paldam and Doucouliagos (2008) for examples from economics, including an analysis of how policymakers should adjust for biases in early research findings. For medical examples and an overview of problems associated with both medical research and meta studies, see Ioannides et al. (2005, 2006).

21 The so-called Imperial College Study was based on a simulation model worked out for other contagious diseases and parameterized based on data from Wuhan, China. It simulated several social distancing strategies for addressing the new virus (see Ferguson et al., 2020); only the no-adjustment scenario predicted the widely reported huge death rates. The cruise ship Princess Diamond provided an early natural experiment of how the disease spreads and its health effects, but it was a relatively short experiment with a relatively old and wealthy population. Several pieces on the Princess Diamond experience were written up and subsequently published, including Mizumoto et al. (2020) and Rocklöv et al. (2020).
} 
that are initially most plausible to policymakers - as might be generated by differences in regional experiences with a new disease.

As a consequence, in addition to the advantages of fiscal federalism for addressing wellunderstood problems, there are also informational advantages associated with variation in state policies. Just as the best medical treatments are not likely to be discovered if every doctor has to treat every patient in exactly the same way, the best public policies for coping with a new disease are unlikely to be worked out if a single policy is imposed uniformly on an entire nation by its central government. Policies for new diseases, as true of medical treatments, are best discovered through experimentation and analysis of the data generated. For example, the extent to which quarantines of interstate and international travelers, banning large outdoor gatherings, economic "lock downs," and masking requirements actually reduce transmission rates can only be determined by observing and analyzing the effects of different combinations of those policies. All such policies plausibly can be argued to slow the spread of a new air-transmitted pathogen, but the extent to which they do so is important and cannot be determined solely by speculative theorizing based on past experience with other better-understood pathogens.

Variation among state and national policies provides one of the fastest and best possible ways to generate the data necessary to identify the policies that best advance the interests of a state or nation's pivotal voters.

Variations in state policies also diversify and reduce risks associated with error-prone theories and policy recommendations. Rather than placing all of one's eggs in one theoretical or policy basket, federal systems allow risks to be diversified by the multiplicity of policies adopted. Variation among state and local public policies thus simultaneously produce useful data and reduce overall risks. ${ }^{22}$

\section{Differences among internalized norms}

Thus far, we have developed three reasons why ideal policies vary among essentially similar individuals and why the policies adopted tend to vary among states and cities within federal systems. At the individual voter level, such differences occur because of differences in risks associated with age and location, and because of differences in conclusions reached from information acquired and analyzed. State policies are affected by the same factors because those factors affect the policy preferences of pivotal voters, governmental advisors, and elected officials.

The final source of variation examined in this paper is that generated by differences in individual beliefs about the nature of a good life or good society-differences sometimes termed ideological or theological variation. From the perspective of narrowly self-centered

\footnotetext{
22 The variation in rates of Covid-19 vaccination in early 2021 provide such evidence. The most efficient policies were approximately three times as efficient as the worst in terms of per capita inoculations.

It should be acknowledged that some policies are best provided centrally, although far fewer than are actually done so according to the decentralization theorem. Moreover, others that appear to be better provided centrally may be so because of policies regarding inter-state or inter-region mobility. For example, if states can impose temporary quarantines on persons from other states and countries, they can break the chain of interstate and international transmission in the same manner that nations can and have.

It also bears keeping in mind that, according to welfare economics, the optimal level of most externalities is usually greater than zero. It is simply too costly to reduce negative externalities to zero or to increase positive externalties to the point where marginal benefits fall to zero.
} 
individuals (pragmatists), a good life and good society simply maximize his or her longevity, base health, and lifetime income. In contrast, a more broadly self-interested person (an ordinary idealist) takes account of other factors, because they have internalized normative theories that influence their assessments of ideal lifestyles and public policies. Idealists may disagree about public policies because they have internalized different normative theories, even if they are otherwise identical. They may have reached, for example, different conclusions about the extent to which government officials should be empowered to influence or control private lives.

The internalized normative theories of "ordinary idealists" tend to influence rather than fully determine their lifestyles and policy preferences. ${ }^{23}$ An "ordinary" utilitarian, for example, would maximize a weighted aggregate utility function in which his/her own utility or quality of life receives a higher weight than others do, but in which no other person's utility receives a zero weight. In contrast, a Benthamite utilitarian "zealot" or "true believer" would attempt to maximize aggregate utility and would place the same weight on every person's welfare, including his or her own. In both cases, policy preferences and other choices are affected by the non-zero weight given to effects of their choices on others, but more so for true believers than ordinary utilitarians. Variations in the weights used by ordinary utilitarians would similarly affect both private choices and demands for public policies, including those addressing health externalities. Other entirely different normative principles would similarly influence behavior and would induce private actions and policy preferences that differ from those of otherwise similar voters. ${ }^{24}$

The normative theories applied by economists and medical doctors, for example, tend to place different weights on material comfort and longevity. Economists tend to stress average material comforts (maximizing per capital real GDP), whereas doctors and epidemiologists tend to stress average longevity (minimizing excess deaths). Such differences affect the kinds of advice given by specialists to government officials and the public at large. And conclusions reached from such expert advice would generate additional variation in the policy choices of elected officials and government employees. ${ }^{25}$

In the mass media, the terms "red", "purple", and "blue" are often used to characterize differences in the normative theories held by the pivotal voters of different states. If there are just three types of ideological theories, there would be three additional factors would affect voter assessments of the relative merits of alternative public policies. In this manner,

\footnotetext{
23 This terminology is worked out in Congleton (2020a), which contrasts "true believers"-persons whose norms determine most of their choices (saints, zealots, and totalitarians)—with "ordinary idealists", whose internalized norms influence rather than fully determine their choices. Congleton (2020a) focuses on the public choice implications of "true believers" rather than on "ordinary idealists", who are the focus of this section as well as in Congleton (2020b).

24 Ideological interests can be incorporated into the utility functions used in the first parts of the paper by adding another variable to the quality-of-life functions for each stage of life that accounts for the distance between the actual policy, S, and the voter's ideologically ideal one, S**, as in Congleton (1991) or Congleton et al. (2017). For a survey of empirical research demonstrating that ideology does in fact affect public policies, see Potrafke (2018).

Systematic differences among state ideologies is likely to reflect their past histories and migration patterns. That conclusion is implied by Fischer's (1989) and Sowell's (2009) historical overviews of the effects of what might be termed "home culture" on the norms and behaviors of migrants for decades or even centuries after they arrived in the United States.

${ }^{25}$ That difference in normative theories also provides a partial explanation for the finding that doctors live a bit longer on average than an average person, although they are more exposed to disease. See Rimpelä et al. (1987).
} 
conclusions about ideal policies increase from a dozen to three dozen and those associated with median-voter-driven state policies increase from four to twelve. "Appendix 2" provides some data that illustrates the variation in risks, policies, and outcomes among states during the period in which policy makers and voters in the United States attempted to cope with the Covid 19 pandemic.

Such variety again tends to be normatively attractive. If pivotal voters are ordinary idealists, electorally driven state policies tend to advance both the narrow and broad interests of each state's pivotal voters. Federalism thereby advances normative aims beyond those included in mainstream welfare economics. Electorally driven state policies are approximately "ideal" according to the normative and positive theories used by each state's pivotal voters. $^{26}$

\section{Conclusion: Variations in public policies in federal systems are to be expected and are both useful and good}

The foregoing analysis implies that as long as age and location generate differences in health risks and personal income, and as long as information is imperfectly collected and analyzed, and as long as variations in normative theories exist, differences will exist in the expected productivity of health-increasing strategies from the perspective of voters and elected officials. Individual voters will disagree about the ideal strategies for addressing pandemics in their own lives and those that should be adopted by their elected regional and national governments. That is true if individuals are all perfectly informed and narrowly self-interested. It also is true if voters pursue broad rather than narrow interests. And, it is true whenever "newness" leads to different conclusions about the effectiveness of treatments and policies. No single, unique universal ideal policy exists in any of those settings.

During a crisis, choices have to be made quickly with less than ideal levels of data or analysis. In democracies, authority to do so is delegated to elected officials, high-ranking government employees, and their advisors. Insofar those officials are directly or indirectly subject to reelection pressures, they will attempt to take account of pivotal voter assessments of ideal public policies. Variations in those assessments imply that governmental policies for addressing pandemics tend to be diverse when they are implemented by decentralized federal or confederal governments. And, the modal voters of every state are likely to regard the policies adopted by their own state governments to be better than those of other states. ${ }^{27}$

The positive public choice analysis undertaken in this paper provides a coherent explanation for disagreements among experts, voters, and state policies observed during the first year of the Covid-19 pandemic that does not require self-delusion or systematic errors. The normative analysis suggests that the variation in pandemic policies associated with

\footnotetext{
${ }^{26}$ It bears noting that universal norms tend to conflict with federalism because they tend to imply that policies should be universal-national or indeed worldwide - to be fully ideal. However, when the variety of norms is acknowledged and given some weight, federalism provides one of the best ways of advancing a variety of conflicting normative interests even from many such universalist perspectives.

27 The same conclusion would, of course, also be true in a benevolent planner model, if state planners used different social welfare functions, relied on different information, or estimated different health production models or quality of life functions. However, such an analysis would have less connection to policies that are ultimately grounded in democratic politics than the analysis undertaken above.
} 
decentralized governance is generally both useful and good. Such variations advance narrow interests in effective healthcare policies and also advance the broader interests that influence ordinary idealists and welfare economists.

Decentralization can advance diverse interests better than any uniform national policy partly for reasons noted long ago by Oates (1972). In addition, during a new epidemic, differences in public policies can diversify risks and produce data that allows public policies to be improved more rapidly than possible in unitary states because useful data is generated about how different combinations of policies affect the spread of a new pandemic or rates of vaccine development and inoculation. It also allows regional differences in normative theories to affect policies. Federalism thus provides a useful antidote to problems associated with large-scale national governance bound by a uniformity norm. Overall, the analysis suggests that an electorally driven patchwork of state policies tends to be "more optimal" from the perspective of the normative theories internalized by state and local pivotal voters than any single national policy can be.

Proponents of federalism are familiar with similar conclusions reached for other less critical policies - although the informational and normative analyses are new. What this paper does is demonstrate that the normative case for federalism applies to pandemics as well as to more mundane public policies such as education, police, and highway construction. ${ }^{28}$ The same logic applies-if anything with greater force-to emergency settings in which risks are poorly understood and the effectiveness of alternative policies largely is based on speculation rather than complete data and statistical analysis.

That is not to say that all voters will regard their state's policies to be ideal. Persons preferring little or no state intervention and those preferring more extreme interventions will be disappointed by their state's response to the pandemic. Only pivotal voters (or government advisors) are likely to regard their own state's policies to be ideal or at least satisfactory. However, history and other circumstances tend to make the variation in voter conceptions of ideal policies within states narrower than those in nations as a whole, which tends to reduce aggregate disappointments from federal pandemic policies relative to those associated with uniform national policies.

Variety in responses to novel deadly pathogens can improve the effectiveness of public policy as a method of improving the welfare of a nation's citizenry in many ways. In such cases, variety truly may be said to be the spice of life.

\section{Appendix 1: On the dynamics and extent of transmission externalities}

The externalities generated by behavior during a pandemic are complex and multifaceted. For example, there is a sense in which the person(s) that first introduces a contagious deadly pathogen into a virgin territory (one never previously exposed to that pathogen) is causally responsible for all of the subsequent illness and deaths in that territory. If that

\footnotetext{
28 State-level quarantines, in effect, create or can create state-level "bubbles" that reduce interstate externalities from Covid policies. However, they also reduce the economic interconnectedness of states and associated transaction costs, which have economic and other consequences. The same is true of national quarantines for international travel, commerce, or both. No single world or national policy is necessary for even highly contagious diseases when "bubbles" can be created-although it should be acknowledged that all such bubbles leak and that cases may arise in which contagiousness is so high and rapid and the health effects are so severe that even small leaks are important.
} 
person had never arrived or had self-isolated until past the contagious period associated with the disease, no other persons would have suffered from the illness. A similar conclusion can be drawn for every group successively infected. If all had completely self-isolated during the contagious periods of their diseases no other previously uninfected persons would have been infected. Negative externalities thus are generated by the sequence of choices made by all of the individuals in the chain of transmission. In terms of proximate cause, however, externalities are simply the results of decisions made by persons at the previous link in the transmission chain of the pathogen of interest. If each contagious person in the sequence of transmissions infected two other persons, his or her direct external effect is only on the two persons infected by his or her specific behavior.

Insofar as negative health externalties are generated by one's routine patterns of lifeworking, shopping, dining, socializing--decisions that reduce transmission levels by altering one's normal pattern of life can be regarded as behaviors that generate positive externalities. They reduce the extent of transmission relative to the baseline and delay or reduce subsequent infections.

Figure 2 and Table 1 illustrate the typical course of a pandemic in a simplified Oxford model developed as an Excel spreadsheet program that is available at http://rdc1.net/forth coming/Pandemic\%20Simulation\%205\%20(modified\%20Oxford\%20model)\%20\%20.xlsx. It characterizes the effect of pathogen that is, on average, initially spread by each contagious person to two other persons and subsequently to two times the fraction of persons not previously infected in the population. The transmission rate is assumed to be constant, and thus implicitly assumes that the behavior that was typical at the beginning of the pandemic continues throughout. (Later transmission rates may be lower than assumed because of changes in transmission-relevant behavior by individuals. Such effects can also be simulated but are not done so here.) Two and half percent of those infected are assumed to be hospitalized and ten percent of those hospitalized with severe cases are assumed to die. These parametric assumptions are below those suggested by the CDC in their March 19, 2021, release of suggested parameters for planning models of Covid-19 transmission, hospitalization, and deaths, which in turn were well below those suggested by the CDC in March of 2020.

The parameters used produce a peak similar to that experienced in northern Europe and the United State in the winter of 2021, but with cumulative deaths about twice as high as those actually experienced at the time of this paper's writing - partly because of the introduction of effective vaccines at roughly the same time which tend to reduce peak transmissions, serious cases, and deaths. ${ }^{29}$

Note that the complete end of transmission without vaccines occurs when essentially everyone has been infected and is either immune or dead, although transmission rates fall to trivial levels (often referred to as termed herd immunity) well before that occurs. Transmission rates below unity and herd immunity gradually emerge because fewer and fewer susceptible persons remain in each successive period.

\footnotetext{
${ }_{29}$ The CDC parameters can be found at: https://www.cdc.gov/coronavirus/2019-ncov/hcp/planning-scena rios.html. The spreadsheet used for the simulations of Fig. 2 and Table 1 can be found at: http://rdc1.net/ forthcoming/Pandemic\%20Simulation $\% 205 \% 20$ (modified $\% 20$ Oxford $\% 20$ model) $\% 20 \% 20$.xlsx.
} 
$70,000.00$

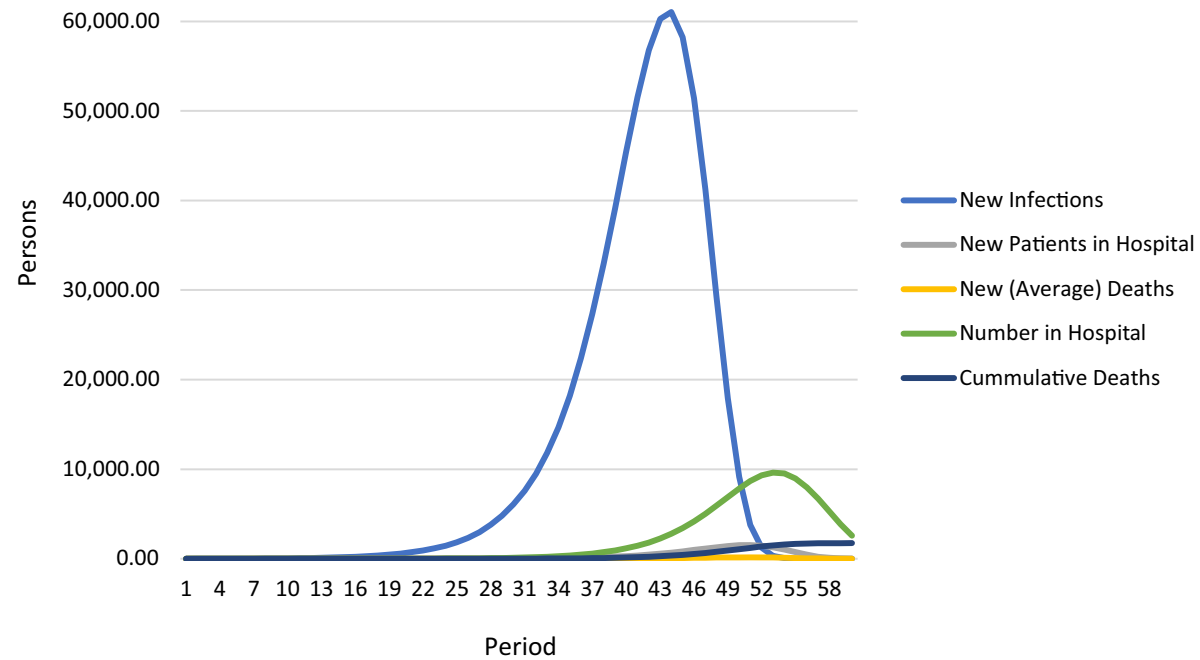

Fig. 2 The path of a stable pathogen-induced pandemic

Table 1 Simulated infections and deaths associated with a stable deadly contagious pathogen

\begin{tabular}{lccccc}
\hline Period & New infections & $\begin{array}{l}\text { New patients in } \\
\text { hospital }\end{array}$ & $\begin{array}{l}\text { New (average) } \\
\text { deaths }\end{array}$ & $\begin{array}{l}\text { Number in hos- } \\
\text { pital }\end{array}$ & Cumulative deaths \\
\hline 1 & 1.00 & 0.0000 & 0.0000 & 0.00 & 0.00 \\
2 & 1.40 & 0.0000 & 0.0000 & 0.00 & 0.00 \\
3 & 1.40 & 0.0000 & 0.0000 & 0.00 & 0.00 \\
4 & 1.40 & 0.0000 & 0.0000 & 0.00 & 0.00 \\
5 & 1.40 & 0.0000 & 0.0000 & 0.00 & 0.00 \\
6 & 1.40 & 0.0000 & 0.0000 & 0.00 & 0.00 \\
7 & 1.40 & 0.0000 & 0.0000 & 0.00 & 0.00 \\
8 & 1.40 & 0.0000 & 0.0000 & 0.00 & 0.00 \\
9 & 3.36 & 0.0350 & 0.0035 & 0.03 & 0.00 \\
10 & 5.32 & 0.0350 & 0.0035 & 0.07 & 0.01 \\
11 & 7.28 & 0.0350 & 0.0035 & 0.10 & 0.01 \\
12 & 9.24 & 0.0350 & 0.0035 & 0.14 & 0.01 \\
13 & 11.20 & 0.0350 & 0.0035 & 0.17 & 0.02 \\
14 & 13.16 & 0.0350 & 0.0035 & 0.21 & 0.02 \\
15 & 15.12 & 0.0350 & 0.0035 & 0.24 & 0.02 \\
16 & 16.46 & 0.0840 & 0.0084 & 0.29 & 0.03 \\
17 & 21.95 & 0.1330 & 0.0133 & 0.39 & 0.05 \\
18 & 30.18 & 0.1820 & 0.0182 & 0.54 & 0.06 \\
19 & 41.15 & 0.2310 & 0.0231 & 0.73 & 0.09 \\
20 & 54.86 & 0.2800 & 0.0280 & 0.98 & 0.12 \\
21 & 71.32 & 0.3290 & 0.0329 & 1.27 & 0.15 \\
\hline
\end{tabular}


Table 1 (continued)

\begin{tabular}{|c|c|c|c|c|c|}
\hline Period & New infections & $\begin{array}{l}\text { New patients in } \\
\text { hospital }\end{array}$ & $\begin{array}{l}\text { New (average) } \\
\text { deaths }\end{array}$ & $\begin{array}{l}\text { Number in hos- } \\
\text { pital }\end{array}$ & Cumulative deaths \\
\hline 22 & 90.51 & 0.3780 & 0.0378 & 1.62 & 0.19 \\
\hline 23 & 108.83 & 0.4116 & 0.0412 & 1.94 & 0.23 \\
\hline 24 & 132.07 & 0.5487 & 0.0549 & 2.36 & 0.28 \\
\hline 25 & 164.08 & 0.7545 & 0.0754 & 2.93 & 0.36 \\
\hline 26 & 208.66 & 1.0288 & 0.1029 & 3.73 & 0.46 \\
\hline 27 & 269.64 & 1.3716 & 0.1372 & 4.82 & 0.60 \\
\hline 28 & 350.81 & 1.7829 & 0.1783 & 6.28 & 0.78 \\
\hline 29 & 455.93 & 2.2627 & 0.2263 & 8.16 & 1.00 \\
\hline 30 & 584.55 & 2.7207 & 0.2721 & 10.47 & 1.27 \\
\hline 31 & 737.65 & 3.3018 & 0.3302 & 13.22 & 1.60 \\
\hline 32 & 923.41 & 4.1019 & 0.4102 & 16.57 & 2.01 \\
\hline 33 & $1,155.25$ & 5.2166 & 0.5217 & 20.76 & 2.54 \\
\hline 34 & $1,451.67$ & 6.7410 & 0.6741 & 26.13 & 3.21 \\
\hline 35 & $1,836.04$ & 8.7702 & 0.8770 & 33.11 & 4.09 \\
\hline 36 & $2,336.35$ & 11.3982 & 1.1398 & 42.25 & 5.23 \\
\hline 37 & $2,983.89$ & 14.6139 & 1.4614 & 54.14 & 6.69 \\
\hline 38 & $3,801.70$ & 18.4413 & 1.8441 & 69.28 & 8.53 \\
\hline 39 & $4,816.51$ & 23.0854 & 2.3085 & 88.27 & 10.84 \\
\hline 40 & $6,064.72$ & 28.8814 & 2.8881 & 111.93 & 13.73 \\
\hline 41 & $7,597.20$ & 36.2916 & 3.6292 & 141.48 & 17.36 \\
\hline 42 & $9,482.46$ & 45.9009 & 4.5901 & 178.61 & 21.95 \\
\hline 43 & $11,807.07$ & 58.4087 & 5.8409 & 225.62 & 27.79 \\
\hline 44 & $14,676.28$ & 74.5973 & 7.4597 & 285.61 & 35.25 \\
\hline 45 & $18,187.27$ & 95.0424 & 9.5042 & 362.21 & 44.75 \\
\hline 46 & $22,405.68$ & 120.4127 & 12.0413 & 459.54 & 56.79 \\
\hline 47 & $27,346.29$ & 151.6179 & 15.1618 & 582.27 & 71.96 \\
\hline 48 & $32,951.93$ & 189.9299 & 18.9930 & 735.91 & 90.95 \\
\hline 49 & $39,067.65$ & 237.0615 & 23.7062 & 927.07 & 114.66 \\
\hline 50 & $45,407.81$ & 295.1767 & 29.5177 & $1,163.84$ & 144.17 \\
\hline 51 & $51,522.80$ & 366.9071 & 36.6907 & $1,456.15$ & 180.86 \\
\hline 52 & $56,763.54$ & 454.6817 & 45.4682 & $1,815.79$ & 226.33 \\
\hline 53 & $60,267.48$ & 560.1420 & 56.0142 & $2,255.52$ & 282.35 \\
\hline 54 & $61,043.66$ & 683.6571 & 68.3657 & $2,787.56$ & 350.71 \\
\hline 55 & $58,216.01$ & 823.7982 & 82.3798 & $3,421.42$ & 433.09 \\
\hline 56 & $51,421.71$ & 976.6913 & 97.6691 & $4,161.05$ & 530.76 \\
\hline 57 & $41,229.45$ & $1,135.1953$ & 113.5195 & $5,001.07$ & 644.28 \\
\hline 58 & $29,289.98$ & $1,288.0700$ & 128.8070 & $5,922.24$ & 773.09 \\
\hline 59 & $17,922.94$ & $1,419.0885$ & 141.9088 & $6,886.64$ & 915.00 \\
\hline 60 & $9,154.89$ & $1,506.6869$ & 150.6687 & $7,833.19$ & $1,065.67$ \\
\hline 61 & $3,785.52$ & $1,526.0916$ & 152.6092 & $8,675.62$ & $1,218.27$ \\
\hline 62 & $1,242.50$ & $1,455.4002$ & 145.5400 & $9,307.22$ & $1,363.81$ \\
\hline 63 & 327.89 & $1,285.5429$ & 128.5543 & $9,616.08$ & $1,492.37$ \\
\hline 64 & 74.83 & $1,030.7361$ & 103.0736 & $9,511.62$ & $1,595.44$ \\
\hline 65 & 16.84 & 732.2496 & 73.2250 & $8,955.80$ & $1,668.67$ \\
\hline
\end{tabular}


Table 1 (continued)

\begin{tabular}{lccccc}
\hline Period & New infections & $\begin{array}{l}\text { New patients in } \\
\text { hospital }\end{array}$ & $\begin{array}{l}\text { New (average) } \\
\text { deaths }\end{array}$ & $\begin{array}{l}\text { Number in hos- } \\
\text { pital }\end{array}$ & $\begin{array}{l}\text { Cumulative deaths } \\
66\end{array}$ \\
\hline 4.26 & 448.0735 & 44.8074 & $7,984.78$ & $1,713.47$ \\
67 & 1.29 & 228.8722 & 22.8872 & $6,706.97$ & $1,736.36$ \\
68 & 0.47 & 94.6380 & 9.4638 & $5,275.51$ & $1,745.83$ \\
69 & 0.20 & 31.0625 & 3.1062 & $3,851.17$ & $1,748.93$ \\
70 & 0.09 & 8.1973 & 0.8197 & $2,573.83$ & $1,749.75$ \\
71 & 0.04 & 1.8707 & 0.1871 & $1,544.96$ & $1,749.94$ \\
72 & 0.02 & 0.4211 & 0.0421 & 813.14 & $1,749.98$ \\
73 & 0.01 & 0.1065 & 0.0106 & 365.17 & $1,749.99$ \\
74 & 0.00 & 0.0323 & 0.0032 & 136.33 & $1,749.99$ \\
75 & 0.00 & 0.0118 & 0.0012 & 41.70 & $1,750.00$ \\
76 & 0.00 & 0.0050 & 0.0005 & 10.64 & $1,750.00$ \\
\hline
\end{tabular}

\section{Appendix 2: On the variety of state level risks, responses, and outcomes}

Table 2 provides evidence of the variety of state circumstances, policies and outcomes associated with the Covid 19 pandemic of 2020-21. State circumstances are characterized by population, degree of urbanization, and the percentage of the population above retirement age. State policies with respect to the pandemic are characterized with vaccination rates as of May 1, 2021, a date chosen because it is about two weeks after daily vaccination rates in the United States peaked according to the CDC. Cumulative Covid-19 deaths as of May 12021 are used to characterized the joint consequences of state circumstances and policies. Data on vaccination rates and deaths are from the CDC's Covid-tracking project; all the other data are from various U. S. Census publications. (Census data for urbanization and population over the age of 65 could only be found for 2010. Atate population data are for 2020.) At the bottom of the table are correlation rates between the circumstance and policy variables and the cumulative Covid-19 related deathrates. All the correlations have the signs anticipated by the theory and, perhaps surprisingly have similar magnitudes, on the order of 20 percent. Deathrates fell with vaccination rates and rose with urbanization and the fraction of state populations of persons above retirement age, as postulated in the models.

The variety of state circumstances is clearly evident in the data presented. Urbanization varies from 38.7 percent in Maine to 95 percent in California. Oldster populations vary from 7.7 percent in Alaska to 17.3 percent in Florida. Cumulative vaccination rates on May 1, 2021 varied from 32.6 percent in Alabama to 60.5 percent in New Hampshire. Cumulative Covid-related death rates varied from 16 per 100,000 in Vermont to 259 per 100,000 in New Jersey. (Means and standard deviations for each variable are tabulate near the bottom of the table.) Cumulative vaccination rates reflect a variety of state policies including allocation schedules and methods of delivery. A few states such as West Virginia reached their maximum daily inoculation rates earlier than the nation as a whole. In those and several of the other cases, the vaccination rates reflect both policies and voter assessments of the new vaccines. (However, supplies of vaccine were still a limiting factor in May of 2021.)

Although the tabulated data do not provide a complete analysis of the models developed above, they are sufficient to demonstrate the variety of state circumstances, policies adopted, and outcomes associated with their particular circumstances and policies. 
Table 2 State level data consistent with the models of pandemic policies

\begin{tabular}{|c|c|c|c|c|c|}
\hline State & Population & Urbanization(percent) & $\begin{array}{l}\text { Popula- } \\
\text { tion }>65 \text { (per- } \\
\text { cent) }\end{array}$ & Vaccination rate & $\begin{array}{l}\text { Cumulative Covid19 } \\
\text { deaths/100 k(percent) }\end{array}$ \\
\hline Alabama & $5,024,279$ & 59.0 & 13.8 & 32.61 & 212 \\
\hline Alaska & 733,391 & 66.0 & 7.7 & 42.06 & 26 \\
\hline Arizona & $7,151,502$ & 89.8 & 13.8 & 40.97 & 219 \\
\hline Arkansas & $3,011,524$ & 56.2 & 14.4 & 35.69 & 197 \\
\hline California & $39,538,223$ & 95.0 & 11.4 & 49.21 & 162 \\
\hline Colorado & $5,773,714$ & 86.2 & 10.9 & 46.83 & 114 \\
\hline Connecticut & $3,605,944$ & 88.0 & 14.2 & 55.19 & 226 \\
\hline Delaware & 989,948 & 83.3 & 14.4 & 47.09 & 149 \\
\hline D. C & 689,545 & 100.0 & 11.4 & 48.4 & 193 \\
\hline Florida & $21,538,187$ & 91.2 & 17.3 & 42.3 & 155 \\
\hline Georgia & $10,711,908$ & 75.1 & 10.7 & 35.16 & 163 \\
\hline Hawaii & $1,455,271$ & 91.9 & 14.3 & 53.22 & 21 \\
\hline Idaho & $1,839,106$ & 70.6 & 12.4 & 34.15 & 110 \\
\hline Illinois & $12,812,508$ & 88.5 & 12.5 & 46.87 & 167 \\
\hline Indiana & $6,785,528$ & 72.4 & 13.0 & 36.37 & 194 \\
\hline Iowa & $3,190,369$ & 64.0 & 14.9 & 44.31 & 188 \\
\hline Kansas & $2,937,880$ & 74.2 & 13.2 & 42.72 & 166 \\
\hline Kentucky & $4,505,836$ & 58.4 & 13.3 & 41.28 & 163 \\
\hline Louisiana & $4,657,757$ & 73.2 & 12.3 & 32.24 & 204 \\
\hline Maine & $1,362,359$ & 38.7 & 15.9 & 55.14 & 57 \\
\hline Maryland & $6,177,224$ & 87.2 & 12.3 & 48.93 & 162 \\
\hline Massachusetts & $7,029,917$ & 92.0 & 13.8 & 56.72 & 190 \\
\hline Michigan & $10,077,331$ & 74.6 & 13.8 & 42.91 & 168 \\
\hline Minnesota & $5,706,494$ & 73.3 & 12.9 & 47.44 & 130 \\
\hline Mississippi & $2,961,279$ & 49.4 & 12.8 & 31.11 & 251 \\
\hline Missouri & $6,154,913$ & 70.4 & 14.0 & 37.87 & 177 \\
\hline Montana & $1,084,225$ & 55.9 & 14.8 & 41.04 & 141 \\
\hline Nebraska & $1,961,504$ & 73.1 & 13.5 & 43.1 & 145 \\
\hline Nevada & $3,104,614$ & 94.2 & 12.0 & 39.88 & 181 \\
\hline New Hampshire & $1,377,529$ & 60.3 & 13.5 & 60.53 & 87 \\
\hline New Jersey & $9,288,994$ & 94.7 & 13.5 & 51.97 & 259 \\
\hline New Mexico & $2,117,522$ & 77.4 & 13.2 & 51.21 & 192 \\
\hline New York & $20,201,249$ & 87.9 & 13.5 & 48.04 & 264 \\
\hline North Carolina & $10,439,388$ & 66.1 & 12.9 & 39.4 & 125 \\
\hline North Dakota & 779,094 & 59.9 & 14.5 & 39.38 & 203 \\
\hline Ohio & $11,799,448$ & 77.9 & 14.1 & 40.6 & 189 \\
\hline Oklahoma & $3,959,353$ & 66.2 & 13.5 & 38.66 & 213 \\
\hline Oregon & $4,237,256$ & 81.0 & 13.9 & 44.34 & 58 \\
\hline Pennsylvania & $13,002,700$ & 78.7 & 15.4 & 50.13 & 210 \\
\hline Rhode Island & $1,097,379$ & 90.7 & 14.4 & 52.96 & 235 \\
\hline South Carolina & $5,118,425$ & 66.3 & 13.7 & 36.74 & 176 \\
\hline South Dakota & 886,667 & 56.7 & 14.3 & 44.96 & 220 \\
\hline Tennessee & $6,910,840$ & 66.4 & 13.4 & 34.51 & 185 \\
\hline Texas & $29,145,505$ & 84.7 & 10.3 & 38.5 & 185 \\
\hline Utah & $3,271,616$ & 90.6 & 9.0 & 39.75 & 74 \\
\hline Vermont & 643,077 & 38.9 & 14.6 & 55.75 & 16 \\
\hline
\end{tabular}


Table 2 (continued)

\begin{tabular}{llllll}
\hline State & Population & Urbanization(percent) & $\begin{array}{l}\text { Popula- } \\
\text { tion }>65(\mathrm{per}-\end{array}$ & Vaccination rate & $\begin{array}{l}\text { Cumulative Covid19 } \\
\text { cent) }\end{array}$ \\
\hline Virginia & $8,631,393$ & 75.5 & 12.2 & 47.52 & 124 \\
Washington & $7,705,281$ & 84.1 & 12.3 & 46.82 & 69 \\
West Virginia & $1,793,716$ & 48.7 & 16.0 & 35.9 & 151 \\
Wisconsin & $5,893,718$ & 70.2 & 13.7 & 45.94 & 138 \\
Wyoming & 576,851 & 64.8 & 12.4 & 34.07 & 94 \\
United States ${ }^{1}$ & $331,449,281$ & 80.7 & 13 & 44.05 & 174 \\
Mean & $6,499,005.51$ & 74.11 & 13.26 & 43.70 & 158.76 \\
St. Deviation & $7,408,022.55$ & 14.89 & 1.65 & 7.14 & 60.20 \\
Correlation with & 0.22 & 0.20 & 0.21 & -0.21 & 1.00 \\
\multicolumn{1}{c}{ Death Rate } & & & & & \\
\hline
\end{tabular}

\section{References}

Batinti, A., \& Congleton, R. D. (2018). On the codetermination of tax-financed medical R\&D and healthcare expenditures: Models and evidence. European Journal of Political Economy, 54, 175-188.

Bentham, J. (1789/1907). An introduction to the principles of morals and legislation. Oxford UK: Clarendon Press.

Buchanan, J. M., \& Stubblebine, W. C. (1962). Externality. Economica, 29(116), 371-384.

Coase, R. H. (1960). The problem of social cost. Journal of Law and Economics, 3, 1-44.

Congleton, R. D. (1991). Ideological conviction and persuasion in the rent-seeking society. Journal of Public Economics, 44(1), 65-86.

Congleton, R. D. (2001). Rational ignorance, rational voter expectations, and public policy: A discrete informational foundation for fiscal illusion. Public Choice, 107(1-2), 35-64.

Congleton, R. D. (2004). The political economy of crisis management: Surprise, urgency, and mistakes in political decision making. Advances in Austrian Economics, 8, 183-203.

Congleton, R. D. (2007). Informational limits to democratic public policy: The jury theorem, yardstick competition, and ignorance. Public Choice, 132(3-4), 333-352.

Congleton, R. D. (2020a). Governance by true believers: Supreme duties with and without totalitarianism. Constitutional Political Economy, 31(1), 111-141.

Congleton, R. D. (2020b). Ethics and good governance. Public Choice, 184, 379-398.

Congleton, R. D., Batinti, A., \& Pietrantonio, R. (2017). The electoral politics and the evolution of complex healthcare systems. Kyklos, 70(4), 483-510.

Doucouliagos, H., \& Paldam, M. (2008). Aid effectiveness on growth: A meta study. European Journal of Political Economy, 24(1), 1-24.

Doucouliagos, H., Paldam, M., \& Stanley, T. D. (2018). Skating on thin evidence: Implications for public policy. European Journal of Political Economy, 54, 16-25.

Ferguson N. M., Laydon, D., Nedjati-Gilani, G., Imai, N., Ainslie, K., Baguelin, M., Bhatia, S., Boonyasiri, A., Cucunubá, Z., Cuomo-Dannenburg, G., Dighe, A., Dorigatti, I., Fu, H., Gaythorpe, K., Green, W., Hamlet, A., Hinsley, W., Okell, L. C., van Elsland, S., Thompson, H., Verity, R., Volz, E., Wang, H., Wang, Y., Walker, P. G. T., Walters, C., Winskill, P., Whittaker, C., Donnelly, C. A., Riley, S., and Ghani, A. C. (2020) Impact of non-pharmaceutical interventions (NPIs) to reduce COVID-19 mortality and healthcare demand. Working Paper, Imperial College London. DOI: https://doi.org/10.25561/ 77482.

Fischer, D. H. (1989). Albion's seed: Four British folkways in America (Vol. 1) of America: A cultural history. Oxford UK: Oxford University Press.

Hays, J. N. (2005). Epidemics and pandemics: their impacts on human history. Santa Barbara CA: ABC-CLIO.

Ioannidis, J. P. (2005). Why most published research findings are false. PLoS medicine, 2(8), e124.

Lau, J., Ioannidis, J. P., Terrin, N., Schmid, C. H., \& Olkin, I. (2006). The case of the misleading funnel plot. $b m j, 333(7568), 597-600$.

Leeson, P. T., \& Thompson, H. A. (2021). forthcoming). Public choice and public health. 
Mizumoto, K., Kagaya, K., Zarebski, A., \& Chowell, G. (2020). Estimating the asymptomatic proportion of coronavirus disease 2019 (COVID-19) cases on board the Diamond Princess cruise ship, Yokohama, Japan, 2020. Eurosurveillance, 25(10), 2000180.

Oates, W. E. (1972). Fiscal federalism. Harcourt Brace Jovanovich.

Pigou, A. C. (1920/2013). The economics of welfare. New York: Palgrave Macmillan.

Potrafke, N. (2018). Government ideology and economic policy-making in the United States-A survey. Public Choice, 174(1-2), 145-207.

Rimpelä, A., Pulkkinen, P., Nurminen, M., Rimpelä, M., \& Valkonen, T. (1987). Mortality of doctors: Do doctors benefit from their medical knowledge? The Lancet, 329(8524), 84-86.

Rocklöv, J., Sjödin, H., \& Wilder-Smith, A. (2020). COVID-19 outbreak on the Diamond Princess cruise ship: estimating the epidemic potential and effectiveness of public health countermeasures. Journal of Travel Medicine. https://doi.org/10.1093/jtm/taaa030

Russell, T. W., Hellewell, J., Jarvis, C. I., Van Zandvoort, K., Abbott, S., Ratnayake, R., \& the CMMID COVID-19 working group. (2020). Estimating the infection and case fatality ratio for coronavirus disease (COVID-19) using age-adjusted data from the outbreak on the Diamond Princess cruise ship, February 2020. Eurosurveillance, 25(12), 2000256

Sowell, T. (2002). A conflict of visions: Ideological origins of political struggles. Basic Books.

Sowell, T. (2009). Black rednecks and white liberals. Encounter Books.

Publisher's Note Springer Nature remains neutral with regard to jurisdictional claims in published maps and institutional affiliations. 